\title{
Inhibition of barnacle (Amphibalanus amphitrite) cyprid settlement by means of localized, pulsed electric fields
}

\author{
Rodolfo E. Pérez-Roa ${ }^{\mathrm{a}}$, Marc A. Anderson ${ }^{\mathrm{a}, \mathrm{b}}$, Dan Rittschof ${ }^{\mathrm{c}}$, Beatriz Orihuela ${ }^{\mathrm{c}}$, Dean Wendt ${ }^{\mathrm{d}}$, \\ Gregory L. Kowalke ${ }^{\mathrm{d}}$ and Daniel R. Noguera ${ }^{\mathrm{a}, \mathrm{b} *}$ \\ ${ }^{a}$ Department of Civil and Environmental Engineering, University of Wisconsin-Madison, 1415 Engineering Hall, Madison, WI \\ 53706, USA; ${ }^{b}$ Environmental Technology and Chemistry Program, University of Wisconsin-Madison, Madison, WI 53706, USA; \\ ${ }^{c}$ Duke University Marine Lab, Beaufort, NC 28516, USA; ${ }^{d}$ Biological Sciences Department, California Polytechnic State \\ University, San Luis Obispo, CA 93407, USA
}

\begin{abstract}
The increasing needs for environmental friendly antifouling coatings have led to investigation of new alternatives for replacing copper and TBT-based paints. In this study, results are presented from larval settlement assays of the barnacle Amphibalanus (=\$Balanus) amphitrite on planar, interdigitated electrodes (IDE), having 8 or $25 \mu \mathrm{m}$ of inter-electrode spacing, upon the application of pulsed electric fields (PEF). Using pulses of $100 \mathrm{~ms}$ in duration, $200 \mathrm{~Hz}$ in frequency and $10 \mathrm{~V}$ in pulse amplitude, barnacle settlement below 5\% was observed, while similar IDE surfaces without pulse application had an average of $40 \%$ settlement. The spacing between the electrodes did not affect cyprid settlement. Assays with lower PEF amplitudes did not show significant settlement inhibition. On the basis of the settlement assays, the calculated minimum energy requirement to inhibit barnacle settlement is $2.8 \mathrm{~W} \mathrm{~h} \mathrm{~m}^{-2}$.
\end{abstract}

\section{Introduction}

Marine biofouling is a problem for any structure immersed in the sea, including ships' hulls, docks, buoys and submerged sensors. Current research on protective antifouling (AF) coatings has been stimulated by concerns about the fate of toxic agents released by the paints manufactured for this purpose (Champ 2000). Research in this area has been devoted to the creation of natural or synthetic polymers with engineered patterns, surface charge or active groups that can either prevent adhesion of marine organisms (AF coatings) or reduce the strength of adhesion in such a way that a small shear stress can remove attached organisms (fouling release coatings) (Clare et al. 1992; Callow and Callow 2002; Owae 2003; Bhadury and Wright 2004).

This study addresses the application of pulsed electric fields (PEF) for AF purposes. The efficacy of this approach is dependent on an ability to produce high-strength electric fields with low voltages (ie $<25 \mathrm{~V}$ ). Previously, Abou-Gazala and Schoenbach (2000) used high-voltage pulsed fields (in the $\mathrm{kV}$ range) to effectively produce temporary stunning of larvae and propagules for pipe protection. Low-voltage, continuous fields of alternating potentials have been tested as AF alternatives to protect fishing nets (Matsunaga et al. 1998) and seawater intakes (Wake et al. 2006). Coatings based on the electrochemical release of chlorine bubbles (Chyou San-Der et al. 2003) and zinc ions (Dowling and Khorrami 2004) using low, variable voltages have been patented.

To date, marine biofouling tests using low-voltage PEF have not been reported. Therefore, this study addressed the impact of PEF on the fouling of microarranged planar electrodes with the spacing between counter-electrodes reduced to a few microns. Low voltages $(0.5-5 \mathrm{~V})$ applied to these assemblies showed that PEFs could significantly inhibit the formation of bacterial biofilms on surfaces subjected to the application of these pulses (Pérez-Roa et al. 2006). The use of PEFs in field applications, however, requires being effective against not only bacteria, but also against macrofouling organisms. The results presented here correspond to laboratory-scale experiments related to the effect of PEFs on the settlement of cyprids of the barnacle Amphibalanus (= Balanus) amphitrite (Pitombo 2004; Clare and Hoeg 2008), a cosmopolitan temperate and tropical marine fouler and a model organism for evaluating AF coatings (Grunlan et al. 2004; Tang et al. 2005). 


\section{Materials and methods}

\section{Interdigitated electrodes}

The test platform consisted of parallel titanium strips or electrodes printed via lithographic techniques onto a non-conductive substratum of borosilicate glass (manufactured by Intelligent MEMS Design, Ontario, Canada). Each alternate electrode terminated at one of two common edges or collectors, in effect forming an interdigitated electrode (IDE) assembly (Figure 1). The IDE configuration was akin to two overlapping combs, with the prongs (ie the titanium strips) of one comb adjacent and non-contacting the prongs of the other comb (Van Gerwen et al. 1998). The width of the metal strips and distance between adjacent strips were only a few micrometer, in order to produce localised, high-strength electric fields. All IDEs were manufactured with strip widths $\left(w_{\text {st }}\right)$ equal to the interstrip spacings $\left(w_{\mathrm{sp}}\right)$. Two different IDE designs were used, having $w_{\text {st }}$ of 8 and $25 \mu \mathrm{m}$, respectively. Each of the two contiguous electrode assemblies per IDE was connected to a voltage source through the collectors. The dimensions of the active area (ie the surface covered by the interdigitated structure) were 17.5 $\mathrm{mm} \times 20 \mathrm{~mm}$, for both IDE types.

\section{Pulsed field configurations}

The characteristics of the pulses applied during barnacle settlement experiments are schematically depicted in Figure 2. These experiments were designed to evaluate the effects of polarity, pulse duration and amplitude, over pulse cycles of $3 \mathrm{~s}$ having $5 \mathrm{~ms}$ pulse periods (i.e. pulses with a frequency of $200 \mathrm{~Hz}$ ). Studies on the effect of amplitude were performed using pulses having duration of $100 \mathrm{~ms}$ and negative polarity. Pulses of $10 \mathrm{~V}$ in amplitude were tested at both polarities and at two levels of pulse duration (10 and $100 \mathrm{~ms}$ ). The influence of inter-electrode spacing was

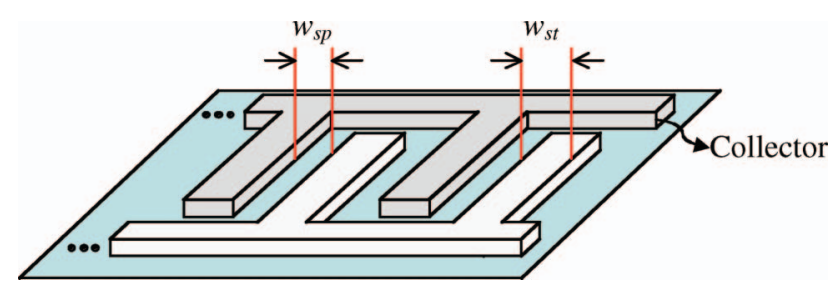

Figure 1. Schematic of IDE. The opposite electrodes form an interdigitated structure; an electric field between consecutive strips is formed upon the application of an external potential carried by the collectors. The width of the electrode strips $\left(w_{\text {st }}\right)$ was equal to the spacing between electrodes $\left(w_{\mathrm{sp}}\right)$. Nomenclatures and figure adapted from Van Gerwen et al. (1998). studied at three voltages $(-5,-7.5$ and $-10 \mathrm{~V})$, for pulses with $100 \mathrm{~ms}$ in duration.

\section{Barnacle drop assays}

Prior to each experiment, the IDE devices were cleaned by gently scrubbing with acetone, followed by a twostep cleaning on a Bransonic 2510 sonicator (Branson Inc, Danbury, CT), first using an enzymatic detergent (Terg-a-zyme ${ }^{\circledR}$, Alconox, White Plains, NY) for $1 \mathrm{~h}$, and then with a solution containing $10 \% \mathrm{v} / \mathrm{v}$ of nitric acid for an additional hour. After sonication, the electrodes were rinsed again with acetone, air-dried and baked for $2 \mathrm{~h}$ at $250^{\circ} \mathrm{C}$.

The barnacle drop settlement assays (Pechenik et al. 1993) were performed adapting procedures described elsewhere (Tang et al. 2005). Briefly, a drop $(200 \mu \mathrm{l})$ of seawater containing $28 \pm 18$ cyprids (the larval settlement stage of barnacles) was placed on each test slide and incubated at room temperature $\left(\sim 23^{\circ} \mathrm{C}\right)$, under ambient light and 100\% humidity. The slides were stored in Petri dishes with wet paper towels placed inside each dish to provide sufficient moisture such as to prevent desiccation of the drop during the experiment. Experiments were continued until at least $\sim 40 \%$ of the barnacles had settled on non-pulsed IDEs (2-3 days). The set of tested slides included: (a) plain glass slides, (b) plain titanium foil, (c) non-pulsed IDE devices and (d) pulsed IDE devices. At least four replicates were performed for each of the tested pulse configurations.

During these experiments, electric fields with amplitudes lower or equal to $10 \mathrm{~V}$ were supplied using a multiple channel pulse generator (PCI 6723, National Instruments). An external signal generator (Wavetek Datron 29A) connected to a power amplifier (HP 6824A) was used for generating pulses with amplitudes higher than $10 \mathrm{~V}$. A computer running LabVIEW ${ }^{\circledR}$ virtual instruments controlled both pulsing systems.
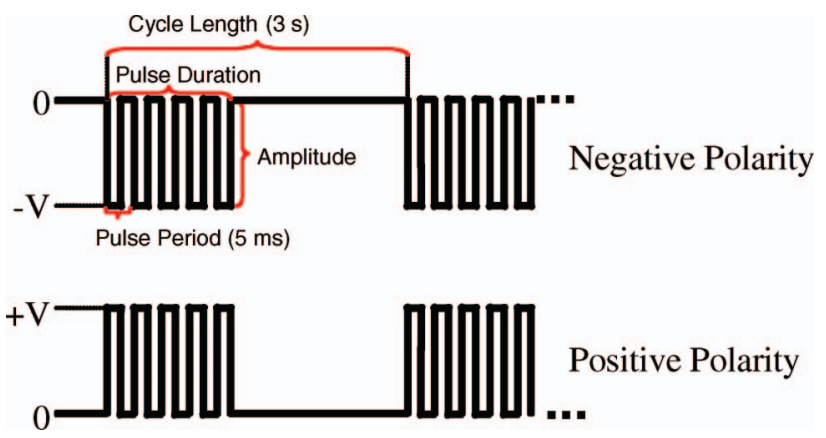

Figure 2. Pulse field characteristics. In these studies, all the pulses had a period of $5 \mathrm{~ms}$ (equivalent to a frequency of 200 $\mathrm{Hz}$ ) and a total cycle length of $3 \mathrm{~s}$. 
An external oscilloscope (Tektronix TDS 1001B) and an OhmRanger variable resistor (Ohmite Mfg. Co, Rolling Meadows, IL) were used to measure rootmean-square (RMS) currents passing through the electrodes and to visualise the pulsed fields that were applied. Separate measurements of electric potentials versus a standard calomel electrode (SCE) were performed by placing a pulsed electrode in a glass beaker containing artificial seawater (Kester et al. 1967), and measuring voltages using the oscilloscope.

At the end of the experimental period, the fraction of barnacles that settled was calculated for each slide. Settled organisms were visually identified by their change in morphology, from larvae to pinhead barnacle (Crisp 1988). After quantification according to morphological changes, the slides were slowly immersed in deionised water to remove the non-settled cyprids from the slide, while settled barnacles remained attached. This rinsing (immersion) procedure was performed with special care so as to minimise shear forces on the slide surface that could induce detachment of lightly adhered cyprids. For documentation purposes, each slide was photographed before and after rinsing with water, using a digital photographic SLR camera (Canon EOS xTi) equipped with a macro lens. At the end of each experimental run, the electrodes were scrubbed and cleaned as described previously for use on successive experimental runs. A total of four experimental sessions were performed. For each of these sessions, pulsed and control IDE devices were randomly chosen from the pool of cleaned slides.

\section{Statistical analysis}

All statistical comparisons were performed using the free software R (www.r-project.org), as well as Sigmaplot ${ }^{\circledR}$ and Sigmastat $^{\circledR}$ (Systat Corporation). Welch's type $t$-tests were primarily used to compare data. Specific data sets that did not distribute normally were assessed using Mann-Whitney tests on ranks. A non-normal distribution occurred since some pulse configurations showed skewed distributions with repeated $0 \%$ settling ratios. A $p$-value of 0.05 or less was considered statistically significant for all comparisons.

\section{Results}

Settlement experiments had a duration that corresponded to $\sim 40 \%$ settlement on control surfaces. Using slides containing non-pulsed IDEs to define the duration of the experiments, the average barnacle settlement $(s)$ on four types of non-pulsed slides tested (Figure 3) was at minimum for glass $(s=38 \% \pm 14 \%$ sd, $n=46)$ and at maximum for titanium $(s=62 \% \pm 14 \%, n=46)$. The IDEs with no pulsing showed settlement between these values. For $8 \mu \mathrm{m}$ IDE devices, the settling ratio was $47 \% \pm$ $11 \%(n=45)$, similar to the results obtained with the $25 \mu$ m electrodes $(s=445 \% \pm 12 \%, n=48)$. With the exception of $8 \mu \mathrm{m}$ and $25 \mu \mathrm{m}$ IDEs, average larval settlement was statistically different in pairwise comparisons $(p=0.028$ for glass vs. $25 \mu \mathrm{m}$ IDE and $p<0.005$ for the rest).

When PEFs with different amplitudes and negative polarity were applied (Figure 4), a reduction in the settlement percentage was evident when the applied voltage was $-10 \mathrm{~V}$. With this amplitude, the effectiveness of the PEF in preventing barnacle settlement was significant. Average settlement was $s=2 \% \pm 3 \%$ $(n=+6)$ for the $25 \mu \mathrm{m}$ IDEs and $s=5 \% \pm 2 \%$, $(n=44)$ for the $8 \mu \mathrm{m}$ IDEs. The observed settlement resulted from some of the replicate experiments completely inhibiting settlement, while other replicates had one or two settled barnacles (Figure 5).

There was no statistically significant difference between the settlement on 8 and $25 \mu \mathrm{m}$ IDE devices for these experiments (Figure 4), showing that, at least

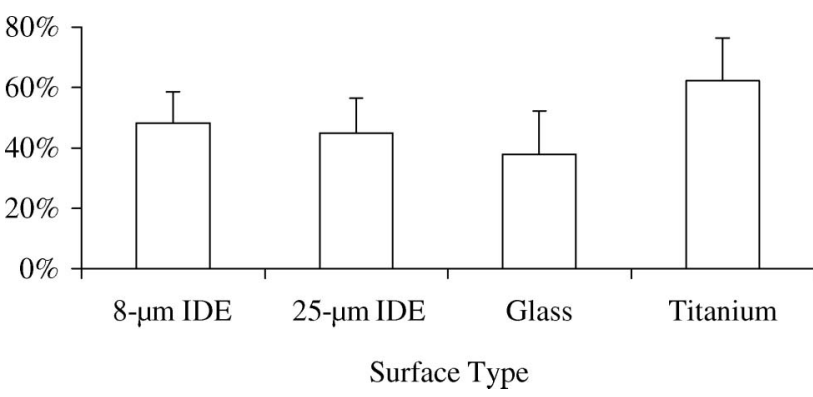

Figure 3. Larval settlement on control surfaces. Nonpulsed IDEs were used to define the duration of the settling experiments so that their average settling ratio was $\sim 40 \%$.

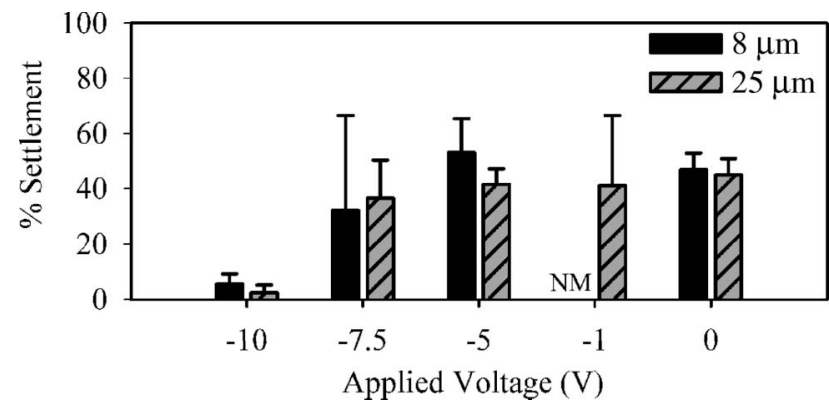

Figure 4. Influence of voltage and inter-electrode spacing on barnacle settlement on IDE assemblies. These results were obtained using negative pulses of $100 \mathrm{~ms}$ in duration over a $3 \mathrm{~s}$ cycle. Settlement on $8 \mu \mathrm{m}$ devices was not measured (NM). 


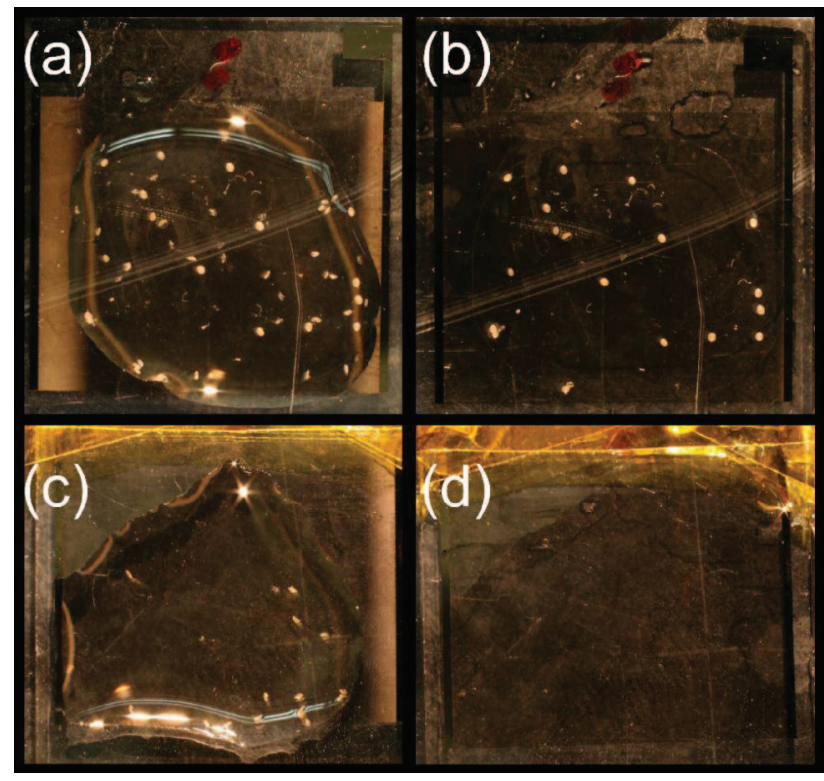

Figure 5. Images of $25 \mu \mathrm{m}$ IDE devices at the end of the experimental period, for two different configurations. The panels on the left (a and c) correspond to the slides containing a drop with barnacle cyprids. The panels on the right ( $b$ and $d$ ) correspond to the same slides, but after rinsing with deionized water. The unattached organisms were flushed away, thus only the settled barnacles remained on the slides. Panels $\mathrm{a}$ and $\mathrm{b}$ correspond to a control IDE not subjected to PEFs $(s=\nless 47 \%)$; panels c and d are from a slide subjected to negative pulses of $-10 \mathrm{~V}$ amplitude and $100 \mathrm{~ms}$ duration $(s=\Theta \%)$.

for the pulse amplitudes studied, inter-electrode spacing did not play a critical role in settlement inhibition. An experiment with $-25 \mathrm{~V}$ in amplitude resulted in electrode damage noted by dissolution of the titanium strips on parts of the IDE and a blue coloration on other areas of the IDEs.

In another set of experiments, the effect of pulse duration and polarity were evaluated. Figure 6 summarizes settlement results obtained in a two-level, two-factor evaluation using a magnitude of $10 \mathrm{~V}$ in amplitude (ie +10 and $-10 \mathrm{~V}$ ) and $25 \mu \mathrm{m}$ IDE devices. A 10 -fold reduction in pulse duration (from 100 to $10 \mathrm{~ms}$ ) rendered the PEFs ineffective against larval settlement. Reversing polarity, while maintaining $100 \mathrm{~ms}$ of pulse application, remained an effective pulse configuration, with $s=\& \pm 11 \%(n=\&)$ with positive pulses, a result that was not statistically different from the amount of settlement observed with the application of negative pulses.

In addition to settlement results, currents during PEF application were measured to assess energy needs, as well as to detect differences between PEF of +10 and $-10 \mathrm{~V}$. The average current values for each voltage tested are shown in Table 1, for both IDE types used in the settling experiments. Currents

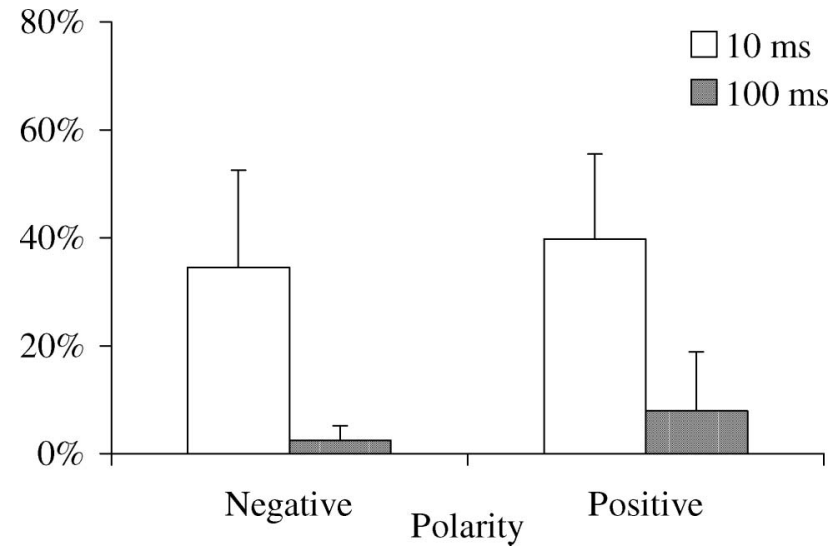

Figure 6. Effects of polarity and pulse duration on settling ratio, using $10 \mathrm{~V}$ pulses on $25 \mu \mathrm{m}$ IDE devices.

Table 1. Average measurements of RMS currents for each PEF configuration and IDE spacing.

\begin{tabular}{lccccc}
\hline $\begin{array}{l}\text { IDE } \\
\text { spacing } \\
(\mu \mathrm{m})\end{array}$ & \multicolumn{5}{c}{ Average currents $\left(\mathrm{mA}_{\mathrm{RMS}}\right)$} \\
\cline { 2 - 6 } & $+10(\mathrm{~V})$ & $-10(\mathrm{~V})$ & $-7.5(\mathrm{~V})$ & $-5(\mathrm{~V})$ & $-1(\mathrm{~V})$ \\
\hline 8 & $\mathrm{NM}$ & $5.3 \pm 0.6$ & $1.9 \pm 1.1$ & $1.2 \pm 0.5$ & $\mathrm{NM}$ \\
25 & $4.3 \pm 1.1$ & $4.8 \pm 1.1$ & $2.7 \pm 0.8$ & $2.5 \pm 0.6$ & $0.3 \pm 0.2$ \\
\hline
\end{tabular}

$\mathrm{NM}=$ combinations not measured in these experiments.

delivered on $25 \mu \mathrm{m}$ IDEs were higher than those on $8 \mu \mathrm{m}$ devices at voltages of -5 and $-7.5 \mathrm{~V}$ and similar when $-10 \mathrm{~V}$ were applied. Measurements showed that currents at -10 and $+10 \mathrm{~V}$ were similar $(4.8 \pm 1.1$ and $4.3 \pm 1.1 \mathrm{~mA}$, respectively).

To further evaluate the effect of reversing polarity on the PEFs delivered to the surface of the IDEs, the potentials of the live and ground connections against a reference electrode (Standard Calomel Electrode, SCE) were measured. An illustration of the voltages observed using an oscilloscope is shown in Figure 7. The potential at the working electrode when $+10 \mathrm{~V}$ was applied was similar to the voltage at the counter electrode upon $-10 \mathrm{~V}$ pulse application. Therefore, in the symmetrical configuration of the IDEs, switching polarity of the applied voltage merely reversed the function of each of the electrodes, but the electric field generated at the surface of the IDEs was the same. This observation was in agreement with the settlement data summarized in Figure 6.

Data obtained from the output of the oscilloscope also showed that, regardless of the sign of the applied voltage, the potential was higher in magnitude on the positive side (approximately $6.5 \mathrm{~V}$ vs. $-3.5 \mathrm{~V}$ in the negative side), which corresponds to the working 


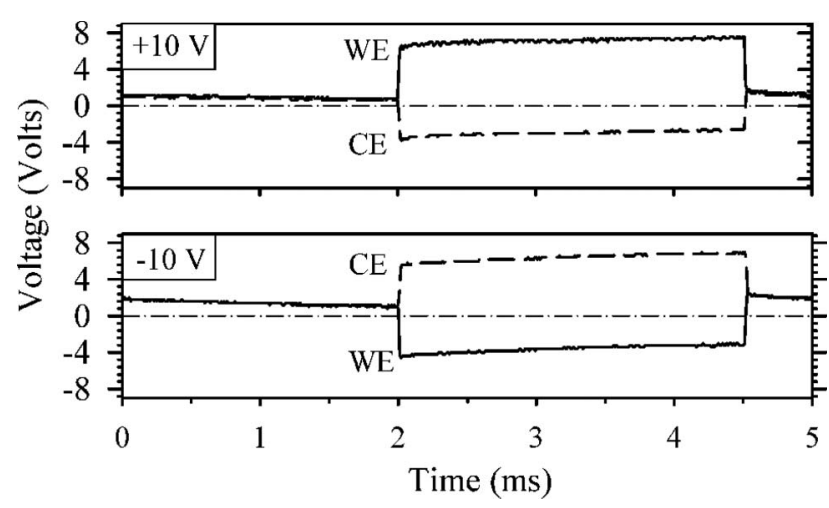

Figure 7. Oscilloscopic view of an electric field pulse applied to an IDE device. The potential of the working (WE) and counter (CE) electrodes were measured against a standard electrode, for an applied PEF of $+10 \mathrm{~V}$ (top) and $-10 \mathrm{~V}$ (bottom). The straight lines show the $0-\mathrm{V}$ level. Both cases produced a similar pattern in voltage distribution, only reversing the electrodes carrying positive and negative potentials.

electrode for $+10 \mathrm{~V}$ and to the counter-electrode for $-10 \mathrm{~V}$ pulses. The unbalanced voltages suggested the presence of electrochemical reactions, occurring at different potentials on each of the two electrodes.

\section{Discussion}

These experiments demonstrate that PEFs are inhibitors of barnacle larval settlement. Under the conditions tested, pulses having $10 \mathrm{~V}$ in amplitude and $100 \mathrm{~ms}$ in duration were effective, while pulses with lower amplitude and shorter durations were not effective. The IDE devices allow the production of a localized, high-strength electric field. The short distance between contiguous electrode strips of opposite charge could have increased ionic activity, which may boost electrochemical activity on the surface. Thus, the mechanisms underlying settlement inhibition might be related to field strengths, electrochemical processes, or a combination of both factors.

In regard to field strength, the average field magnitude as a function of the distance from the electrode surface was estimated using the equations proposed by Van Gerwen et al. (1998), which are specific for IDEs (Figure 8). Van Gerwen's model returns the spatial distribution of the electrical potential as a function of the applied voltage, the spacing between consecutive electrodes ( 8 or $25 \mu \mathrm{m}$ in the study reported here), and the width of each electrode strip (which are equivalent to the electrode spacing for IDE devices in the study reported here). Although those equations assume that the voltage is

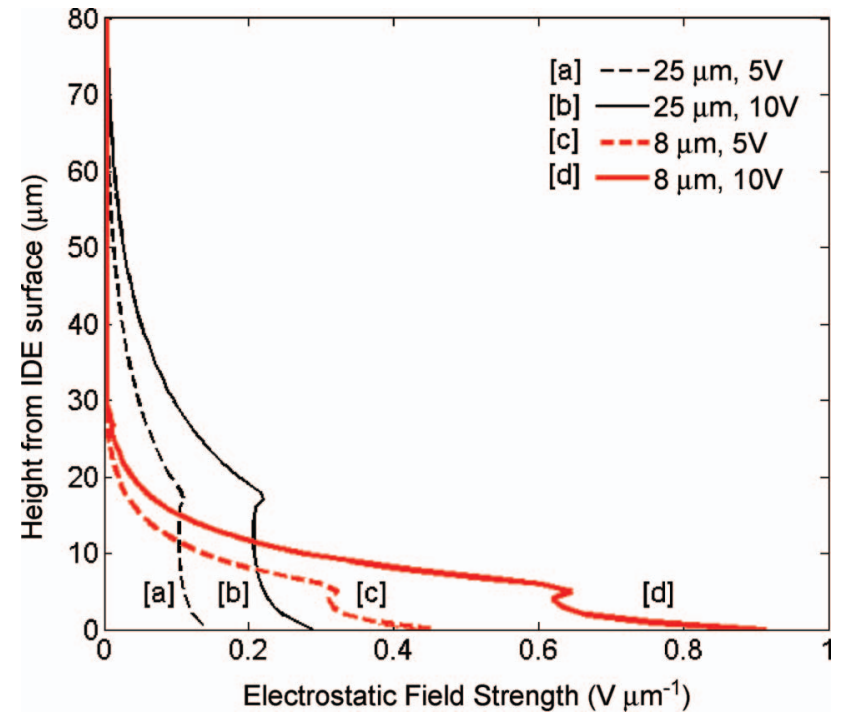

Figure 8. Theoretical average electric field strength as a function of distance from the IDE surface, for devices with interelectrode spacings of 8 and $25 \mu \mathrm{m}$ and applied voltages of 5 and $10 \mathrm{~V}$.

being distributed equally between both electrodes (which was not true in experiments reported here), they provide a good initial approximation. The results shown in Figure 8 are for applied voltages of 5 and $10 \mathrm{~V}$. As shown by line [b] in the figure, a $25 \mu \mathrm{m}$ IDE device and $10 \mathrm{~V}$ would produce a field of $\sim 0.2 \mathrm{~V} \mu \mathrm{m}^{-1}$ in magnitude in the first $20 \mu \mathrm{m}$ from the surface. This configuration was shown to be effective in biofouling inhibition (see Figure 4). However, a voltage of $5 \mathrm{~V}$ in an $8 \mu \mathrm{m}$ IDE would produce similar and even a higher field strength (line [c] in Figure 8) in the first $10 \mu \mathrm{m}$ above the surface. Note, however, that this voltage did not affect barnacle settlement. Thus, these theoretical estimations suggest that the strength of the electrostatic field cannot be directly linked to the effectiveness of PEFs in preventing macrofouling. Nonetheless, the settling inhibition results obtained with PEF of $10 \mathrm{~V}$ suggest that voltage is important. This could be due to the effect of voltage on electro-osmotic flows, produced by concentration gradients on the surroundings of the IDE strips, since shear stresses, induced by these electro-osmotic flows, might discourage settlement (Mullineaux and Butman 1991). Moreover, it may be possible that PEF application generates an electro-wetting phenomenon that could generate a more hydrophilic surface and discourage barnacle settling. Throughout the experiments, increases on the area wetted by seawater drops on the IDE surfaces were qualitatively evaluated. However, a clear correlation between PEF application (ie applied voltage) and the extent of wetting (ie increases on IDE surface covered by the seawater 
drop) was not detected. To directly evaluate the possibility of PEF induced electro-wetting, the percentage of IDE area covered by a seawater drop was measured at the beginning and end of a 2-day experiment, using the PEF conditions that were successful in inhibiting barnacle settling (ie $-10 \mathrm{~V}$ in magnitude, $200 \mathrm{~Hz}$ in frequency and $100 \mathrm{~ms}$ in duration over 3-s cycles). On average, the drops placed over pulsed and non-pulsed IDEs experienced a $5 \%$ increase in size, with no statistical difference noticed between pulsed and non-pulsed experiments, supporting the observed lack of correlation between PEF application and wetting. Thus, it is not possible to conclude that electro-wetting significantly affected barnacle settlement.

Alternatively, it is likely that electrochemical processes at the electrode surface also played a significant role in settlement inhibition. Evidence of electrochemically-induced corrosion on the material was observed when pulses of $-25 \mathrm{~V}$ were applied, as noted by the disintegration of part of the IDEs and the blue coloration on the electrodes. With an amplitude of $-10 \mathrm{~V}$, formation of a gold coloured layer on the titanium strips was observed. It is possible that this coloration was due to the development of an amorphous titanium oxide film $\left(\mathrm{TiO}_{2}\right)$, as reported by Wake et al. (2006) on titanium electrodes used in electrochemical AF systems. Superficial electrode corrosion was unlikely to happen with $10-\mathrm{V}$ PEFs on $25 \mu \mathrm{m}$ electrodes; otherwise, electrode trans-passivation would have produced increased current flows due the migration of titanium ions into the liquid medium, but current measurements did not show evidence of such phenomenon. Rather, currents follow a linear relationship with voltage, as expected when an oscillating pulse (ie a $200 \mathrm{~Hz}$ wave) is applied into a solid-liquid system. IDEs with $8 \mu \mathrm{m}$ might have been affected by corrosion, but no morphological change or loss in AF performance was detected after successive experiments.

In regard to the possibility that electrochemical byproducts were generated and contributed to the inhibition of settlement, there was no evidence of bubble formation, which could be indicative of reactions leading to water splitting and chlorine formation. The lack of bubbling even with amplitudes as high as $10 \mathrm{~V}$ suggests that the frequency used on these pulses $(200 \mathrm{~Hz})$ imposed kinetic limitations on those reactions. Park et al. (2004) described a similar phenomenon by testing the electrochemical production of chlorine using alternating currents with 5, 16 and $50 \mathrm{~Hz}$ of frequency. They showed that $\mathrm{Cl}_{2}$ production decreased as the frequency was increased, with $\mathrm{Cl}_{2}$ formation close to detection limits at $50 \mathrm{~Hz}$. Moreover, alternating currents with $60 \mathrm{~Hz}$ or higher frequencies have been used for electrical sterilization by heating without water splitting reactions (Amatore et al. 1998; Uemura and Isobe 2002; Samaranayake et al. 2005).

In the absence of water splitting or chlorine formation, other possible electrochemical reactions upon the application of PEFs to the IDEs could be the formation of reactive oxygen species such as hydroxyl and superoxide radicals. Jeong et al. (2006) found that these species were involved in the electrochemical inactivation of $E$. coli under chlorine-free conditions, which could be a possible scenario for settlement inhibition in the present study. Indeed, oxygen reduction and hydrogen peroxide production have been reported in anodically produced $\mathrm{TiO}_{2}$ (Clechet et al. 1979; Mentus 2004). Moreover, Wake et al. (2006) presented a similar conclusion regarding the involvement of reactive oxygen species on electrochemical AF processes using titanium electrodes. Thus, further investigation of these systems is necessary in order to evaluate the importance of reactive oxygen species formation on the inhibition of barnacle settlement.

The experiments with different pulse amplitudes showed that barnacle settlement was only prevented with amplitudes as high as $10 \mathrm{~V}$. In addition, pulses of short duration were not effective against settlement. Taken together, these observations suggest that there is a minimum energy requirement to achieve electrochemical settlement inhibition. Since practical PEF application would depend on whether energy requirements are low enough to at least outperform cleaning procedures associated with biofouling, energy consumption was assessed by measuring currents for each pulsed slide. Energy consumption was calculated according to Equation 1, where $E$ corresponds to the energy used per unit of time (expressed in $\mathrm{W} \mathrm{h}^{-1}$ ), $V$ to the applied voltage, $I_{\mathrm{RMS}}$ to the measured root mean square current, $P$ to the pulse duration (10 or $100 \mathrm{~ms}$ ), and $L$ to the cycle length ( $3 \mathrm{~s}$ for all these experiments). Thus, the ratio $P / L$ indicates the fraction of the time when the power is effectively turned on.

$$
E=\psi \cdot \Psi_{\mathrm{RMS}} \cdot \frac{P}{L}
$$

For each pulse configuration used in this study, data from positive and negative polarities were pooled for the calculation of energy consumption, since they are basically the same (as discussed earlier). The estimated energy consumption was plotted against mean settlement percentages, as shown in Figure 9. This figure defines a minimum energy requirement $\left(\sim 0.7 \mathrm{~mW} \mathrm{~h}^{-1}\right)$ to reduce cyprid attachment. In terms of the energy expense per unit of active area, effective settlement inhibition required $\sim 2.8 \mathrm{~W} \mathrm{~h}^{-1} \mathrm{~m}^{-2}$ 


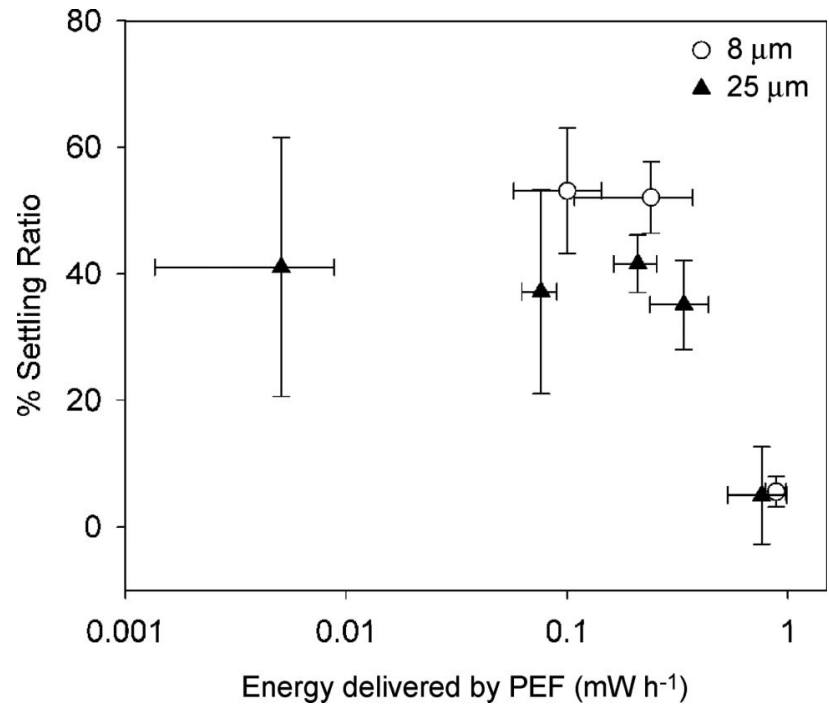

Figure 9. Energy requirements and settling ratios for each PEF configuration tested. A cycle length of $3 \mathrm{~s}$ was used in these experiments.

(the effective surface area of the electrodes was $2.4 \pm 0.4 \mathrm{~cm}^{2}$ ). This energy value is higher than the one reported by Wake et al. (2006) for an AF study using galvanometrically activated titanium plates in a field system $\left(0.3-0.6 \mathrm{~W} \mathrm{~h}^{-1} \mathrm{~m}^{-2}\right.$ or, equivalently, $50-100 \mathrm{~mA} \mathrm{~m}^{-2}$ of current with an average voltage of $6 \mathrm{~V}$ vs. $\mathrm{Ag} / \mathrm{AgCl}$ reference electrode). Voltage drops occurring at the counter electrode were not reported in that study, thus a direct comparison with the present results cannot be established. By only considering the voltage drop between the oxidized electrode (ie the one achieving $\sim+7 \mathrm{~V}$ ) and the reference, energy requirements would decrease by $\sim 30 \%$ (ie down to $\sim 2 \mathrm{~W} \mathrm{~h}^{-1} \mathrm{~m}^{-2}$ ).

In summary, the present experiments demonstrated that PEF inhibited settlement of $A$. amphitrite cyprids with low voltages. The system needs to be optimized in terms of energy consumption. The relevance of possibly generating reactive species under the highstrength electric fields produced needs to be investigated. These follow-up studies are key to understanding the effects and limitations of externally applied potentials (and currents) on the prevention of biofouling. At the scale of the IDE devices tested (millimetres to centimetres), the anti-biofouling technique presented in this study should be applicable to small devices, such as marine sensors, whose reliability and autonomy is strongly related with their ability to keep off biofouling agents (Whelan and Regan 2006). However, practical applications of PEF on a larger scale would likely require geometries other than the IDE architecture.

\section{Acknowledgements}

We gratefully acknowledge the US Office of Naval Research (ONR) for providing the funding for this project under the contract N0014-03-1-0647. We also thank Dr Dean Tompkins and Dr Isabel Tejedor (University of Wisconsin) for their useful comments, undergraduate research assistant Richard Niemer for his help on the experimental setup, and Gary Dickinson (Duke University Marine Lab) for his editorial comments.

\section{References}

Abou-Ghazala A, Schoenbach KH. 2000. Biofouling prevention with pulsed electric fields. IEEE Trans Plasma Sci. 28(1):115-121.

Amatore C, Berthou M, Hebert S. 1998. Fundamental principles of electrochemical ohmic heating of solutions. J Electroanal Chem. 457(1-2):191-203.

Bhadury P, Wright PC. 2004. Exploitation of marine algae: biogenic compounds for potential antifouling applications. Planta. 219(4):561-578.

Callow M, Callow J. 2002. Marine biofouling: a sticky problem. Biologist. 49:1-5.

Champ MA. 2000. A review of organotin regulatory strategies, pending actions, related costs and benefits. Sci Total Environ. 258(1-2):21-71.

Chyou San-Der S, Wen-Chi Chiang K, Ran Huang K, JiannKuo Wu K. 2003. Taiwan Power Company, Taipei, Assignee. Feb 4, 2003. Anti-biofouling system. US Patent No. $6,514,401$.

Clare AS, Hoeg JT. 2008. Balanus amphitrite or Amphibalanus amphitrite? A note on barnacle nomenclature. Biofouling. 24(1):55-57.

Clare AS, Rittschof D, Gerhart DJ, Maki JS. 1992. Molecular approaches to nontoxic antifouling. Invert Reprod Devel. 22(1-3):67-76.

Clechet P, Martelet C, Martin JR, Olier R. 1979. Photoelectrochemical behavior of Tio2 and formation of hydrogen peroxide. Electrochim Acta. 24(4):457-461.

Crisp D. 1988. Reduced discrimination of laboratory-reared cyprids of the barnacle Balanus amphitrite amphitrite Darwin, Crustacea Cirripedia, with a description of a common abnormality. In: Thompson MF, Sarojini R, Nagabushanam R, editors. Marine biodeterioration. Rotterdam: Balkema. p. 409-432.

Dowling D, Khorrami F. 2004. Applied Semiconductor International Ltd, Assignee. Semiconductive corrosion and fouling control apparatus, system, and method. US patent $6,811,681$.

Grunlan MA, Lee NS, Cai GP, Gadda T, Mabry JM, Mansfeld F, Kus E, Wendt DE, Kowalke GL, Finlay JA, et al. 2004. Synthesis of alpha,omega-bis epoxy oligo $\left(1^{\prime \leftarrow} \mathrm{H}, 1^{\prime \leftarrow} \mathrm{H}, 2^{\prime \leftarrow} \mathrm{H}, 2^{\prime \leftarrow} \mathrm{H}\right.$-perfluoroalkyl siloxane)s and properties of their photo-acid cross-linked films. Chem Mater. 16(12):2433-2441.

Jeong J, Kim JY, Yoon J. 2006. The role of reactive oxygen species in the electrochemical inactivation of microorganisms. Environ Sci Technol. 40(19):6117-6122.

Kester DR, Duedall IW, Connors DN, Pytkowicz RM. 1967. Preparation of artificial seawater. Limnol Oceanogr. 12(1):176-179.

Matsunaga T, Nakayama T, Wake H, Takahashi M, Okochi M, Nakamura N. 1998. Prevention of marine biofouling using a conductive paint electrode. Biotechnol Bioeng. 59(3):374-378. 
Mentus SV. 2004. Oxygen reduction on anodically formed titanium dioxide. Electrochim Acta. 50(1):27-32.

Mullineaux LS, Butman CA. 1991. Initial contact, exploration and attachment of barnacle (Balanus amphitrite) cyprids settling in flow. Mar Biol. 110(1):93-103.

Owae I. 2003. General aspects of tin-free antifouling paints. Chem Rev. 103(9):3431-3448.

Park JC, Lee MS, Han DW, Lee DH, Park BJ, Lee IS, Uzawa M, Aihara M, Takatori K. 2004. Inactivation of Vibrio parahaemolyticus in effluent seawater by alternating-current treatment. Appl Environ Microbiol. 70(3):1833-1835.

Pechenik JA, Rittschof D, Schmidt AR. 1993. Influence of delayed metamorphosis on survival and growth of juvenile barnacles Balanus amphitrite. Mar Biol. 115(2): 287-294.

Pérez-Roa RE, Tompkins DT, Paulose M, Grimes CA, Anderson MA, Noguera DR. 2006. Effects of localised, low-voltage pulsed electric fields on the development and inhibition of Pseudomonas aeruginosa biofilms. Biofouling. 22(6):383-390.

Pitombo FB. 2004. Phylogenetic analysis of the Balanidae (Cirripedia, Balanomorpha). Zool Scrip. 33(3):261-276.
Samaranayake CP, Sastry SK, Zhang H. 2005. Pulsed ohmic heating - a novel technique for minimization of electrochemical reactions during processing. J Food Sci. 70(8): E460-E465.

Tang Y, Finlay JA, Kowalke GL, Meyer AE, Bright FV, Callow ME, Callow JA, Wendt DE, Detty MR. 2005. Hybrid xerogel films as novel coatings for antifouling and fouling release. Biofouling. 21(1):59-71.

Uemura K, Isobe S. 2002. Developing a new apparatus for inactivating Escherichia coli in saline water with high electric field AC. J Food Eng. 53(3):203-207.

Van Gerwen P, Laureyn W, Laureys W, Huyberechts G, De Beeck MO, Baert K, Suls J, Sansen W, Jacobs P, Hermans L, et al. 1998. Nanoscaled interdigitated electrode arrays for biochemical sensors. Sens Act BChemical. 49(1-2):73-80.

Wake H, Takahashi H, Takimoto T, Takayanagi H, Ozawa K, Kadoi H, Okochi M, Matsunaga T. 2006. Development of an electrochemical antifouling system for seawater cooling pipelines of power plants using titanium. Biotechnol Bioeng. 95(3):468-473.

Whelan A, Regan F. 2006. Antifouling strategies for marine and riverine sensors. J Environ Monitor. 8(9):880-886. 